\title{
Travel Health - Gaps in Awareness and Practices Among Medical Interns of a Tertiary Care Hospital in India
}

\author{
Jyoti A. Landge ${ }^{1 *}$, Kajal Shrivastava ${ }^{2}$, Swati Ghonge ${ }^{2}$ \\ ${ }^{1}$ Department of Community Medicine, Nootan Medical College and Research Centre, Visnagar, India \\ ${ }^{2}$ Department of Community Medicine, Dr. D. Y. Patil Medical College, Pimpri, Pune, India
}

Corresponding Author: Jyoti A. Landge, MD, Associate Professor, Department of Community Medicine, Nootan Medical College and Research Centre, Visnagar, India. Tel: +91-8087649980, Email: jlandge11@gmail.com

Received June 22, 2020; Accepted October 4, 2020; Online Published November 22, 2020

\begin{abstract}
Introduction: Pretravel health assessments aim to promote risk reduction through preventive measures and safe behaviour. It also ensures that travellers are up-to-date with travel vaccine uptake. However, studies assess pretravel health-seeking practices from a variety of medical and nonmedical sources and vaccine uptake prior to travel to both developing and developed countries. The present study was an effort to address the awareness and practice of pre-travel health care among medical interns of a tertiary care hospital.

Methods: A cross-sectional study was carried out in medical interns of tertiary care hospital. Study participants were Bachelor of Medicine and Bachelor of Surgery (MBBS) interns posted in the preventive medicine departments during the internship program in the same hospital. Awareness and practice of pre-travel health were assessed with help of a preformed self-assessment questionnaire.

Results: Study had 59 (53.6\%) males and 51 (46.4\%) female respondents. All were of Indian origin and 69 (62.7\%) had travelled internationally in the last 5 years. The mean age of study participants was $23.3 \pm 1.3 y$ rs with range of 23-30 years. The majority (69.6\%) of them had travelled abroad for holiday purposes. Most (73.9\%) of them had travelled with family members. Out of 69 who had travelled internationally, $47(68.1 \%)$ had visited a doctor for travel health advice prior to the trip and $29(42 \%)$ had taken the required vaccination for the destination countries in their last international travels. The age and sex of the respondents did not have any statistically significant influence on the uptake of the travel vaccine.

Conclusion: Study findings revealed inadequate awareness and practice of travel medicine among medical interns.

Keywords: Awareness, Practice, Travel, Travel-Related IIlness, Vaccines, Hospitals, India
\end{abstract}

Citation: Landge JA, Shrivastava K, Ghonge S. Travel health - gaps in awareness and practices among medical interns of a tertiary care hospital in India. Int J Travel Med Glob Health. 2020;8(4):152-156. doi:10.34172/ijtmgh.2020.26.

\section{Introduction}

In 21 st century due to rapid industrialisation, advancement in science and technology, and increased tourism, peoples are travelling globally for various purposes (e.g. Job, academic meet, education, business, etc.). World Tourism Organization reports that international travelling for various purposes has increased significantly for a few decades. International travel has increased dramatically over the last few decades both in magnitude, speed and geographical reach with 940 million arrivals reported in 2010. ${ }^{1}$ Such travel exposes individuals to new cultural, psychological, physiological, and microbiological experiences. Travellers play a significant role in the spread of infectious diseases across international borders, through their travel patterns and behaviours.

Travel across the boundaries may be the only risk factor for infectious diseases that are well controlled in the travellers' country of residence, particularly vaccine-preventable diseases such as hepatitis A, typhoid, polio, and measles. ${ }^{2}$

The role of vaccination among travellers is an essential component of national control of travel-associated infectious diseases. Understanding the behaviours of travellers and their attitudes towards a variety of communicable diseases can inform policy aimed at protecting the individual traveller, their contacts, and the communities into which they travel. Behavioural studies of travellers provide insights into the risks of both acquiring and importing infectious diseases. ${ }^{2}$

A pretravel consultation with a health professional can provide an international traveller with the necessary preventive advice on minimizing health risks during travel, including the risk of infectious disease and the opportunity

Copyright $\odot 2020$ The Author(s). This is an open-access article distributed under the terms of the Creative Commons Attribution License (http:// creativecommons.org/licenses/by/4.0), which permits unrestricted use, distribution, and reproduction in any medium, provided the original work is properly cited. 
for relevant vaccination and chemoprophylaxis. Travellers who seek pretravel health advice from a health professional have been found to have a better knowledge of infectious disease risk, more accurate risk perceptions, and a higher level of intended risk-reducing behaviours. ${ }^{3-6}$

Studies have shown that many western travellers do not consult a health professional prior to travel and may not be aware of their need to protect themselves from infectious diseases. ${ }^{7-11}$ Studies on the pretravel health-seeking behaviour of travellers within the Asia Pacific are limited; however, recent evidence suggests that the proportion of Asian travellers seeking pretravel health advice is significantly lower than that of western travellers. ${ }^{11}$

Several conducted surveys have demonstrated that high proportions of travellers are unaware of their travel health risks. In many cases, travellers had not received the immunizations, and medications for prophylaxis despite the range of opportunities for travel health advice available. ${ }^{12-15}$

Every year many medical professionals travel from one country to another for one or more reasons. Being medical professionals, they must be aware of the necessary travel health advisory and follow it. The diverse range of disease burdens across the world and each country with different travel health protocols make it necessary for the medical professional to be aware and practice travel health services. In India, currently, the data is not available on awareness and practice of travel health advisory among travellers as well as medical professionals. This reflects poor monitoring and adherence to travel health advisory in the country. Lack of study on awareness among medical professionals reflects a lack of concern toward the importance of travel health. This study explored the awareness and practice of pre-travel health care among medical interns of a tertiary care hospital.

\section{Methods}

A cross-sectional study was carried out in medical interns of tertiary care hospital at Pimpri, Pune, Maharashtra from April 2018 to March 2019. Study participants were Bachelor of Medicine and Bachelor of Surgery (MBBS) interns posted in the preventive medicine departments during an internship program in the same hospital. From a previous study, it was found that $71.4 \%$ of participants had taken the required vaccination for the destination countries in their last international travels ${ }^{15}$ considering the same proportion of calculated sample size using a formula for proportionate sample size with $10 \%$ allowable error at $95 \%$ confidence interval was 79 (Open epi software). A total of 110 study participants were included after obtaining informed consent. A convenience sampling method was applied and participants were approached on a continuous basis until the required sample size was achieved. Interns not willing to participate were excluded from the study. Awareness and practice of pretravel health were assessed with the help of a preformed selfassessment questionnaire. The questionnaire was adapted and modified from previous study ${ }^{16}$ as per requirement in the local context. A pilot study was carried out among ten medical interns using a modified questionnaire for validation. The self-assessment questionnaire consisted of questions related to basic demographic information, history of travel, number of foreign visits during the last five years, knowledge about travel disease, chemoprophylaxis, travel vaccine, and the importance of the pre-travel vaccine. The understanding question consists of the best time to visit traveller's clinic before travel, necessity of pretravel vaccine, advice, and their satisfaction in the earlier pretravel clinic. Knowledge and understanding assessment was done using yes/no response and open-ended questions.

Data were entered in Microsoft Excel 2007. The responses of the participants were statistically analysed using SPSS Version 20. Descriptive analysis for the categorical and continuous variables was performed. Categorical variable results were expressed in frequency (percentages) and continuous variable results were expressed in mean \& SD or Median and quartile range depending on the distribution of the variable.

\section{Results}

One hundred and ten MBBS intern doctors participated in this study, with 59 (53.6\%) males and 51 (46.4\%) female respondents. All were of Indian origin. Out of 110 participants, $69(62.7 \%)$ had travelled internationally in the last 5 years. The mean age of the study participants was $23.4 \pm 1.3 \mathrm{yrs}$ and range of $23-30$ years. The majority $(69.6 \%)$ of them had travelled for the holiday purpose with a mean duration of stay $14 \pm 10.7$ days and a range of 3-60 days. Maximum (73.9\%) had travelled with family.Out of 69 travelling internationally, 47 (68.1\%) had visited a doctor for travel health advice prior to the trip and 29 (42\%) had received the required vaccination for the destination countries in their last international travels. Hepatitis B (75.8\%) was the most received vaccine by the respondents who had travelled internationally. Other received vaccines were hepatitis $\mathrm{A}(34.5 \%)$, influenza (13.8\%), and typhoid (6.9\%) (Table 1).

The age and sex of the respondents did not have any statistically significant influence on the uptake of travel vaccine among the respondents who had embarked on international travel at one point or the others within the last five years prior to this study.

\section{Discussion}

In the present study, the number of male respondents was slightly higher than female respondents. In the study conducted at Oman $^{17}$ and Australia ${ }^{18}$ similar to the present study male respondents were higher in number compared to female respondents; however, in a study conducted in Qatar, female respondents were the predominant group ${ }^{19}$ while in a study conducted in America ${ }^{20}$ there were equal proportions of male and female respondents.

Tourism, visiting family and friends as well as educational visits were the three most common purposes of travel in this study group, which is similar to other studies. ${ }^{10,17,21}$

International travel has dramatically increased during recent years and there has been an increase in diseases and associated public health problems. Each year, 80 million travellers residing in developed countries visit developing countries where the hygienic and epidemiological conditions are fundamentally different from their home country. ${ }^{22}$ 
In the present study, 69 individuals (62.7\%) had travelled internationally in the last 5 years preceding this study and Hepatitis B was the most received vaccine by $75.8 \%$ of the respondents who had travelled internationally. Other received vaccines were Hepatitis A (34.5\%), Influenza (13.8\%), and typhoid (6.9\%). In a study by Hassan et al. ${ }^{15} 63(33.3 \%)$ of the respondents had embarked on at least one international travel in the last 5 years preceding this study and of which $45(71.4 \%)$ had taken the required vaccination for the destination countries in their last international travels. Yellow fever vaccine was the most received vaccine by $82.2 \%$ of the respondents who had travelled internationally. Variation in findings and vaccination could be due to the difference in travelled country and the need for vaccine requirement of the travelled country.

The importance of qualified pre-travel advice consultation is increasing due to the increase in demand at international airports and diseases of international spread concern. The impact of travel medicine on health cannot be ignored in relation to endemic diseases of the country to visit and the spread of disease from travellers to the country of visit. There

Table 1. Baseline Information of Study Participants

\begin{tabular}{|c|c|c|}
\hline Demographics & No. & $\%$ \\
\hline Indian & 110 & 100 \\
\hline \multicolumn{3}{|l|}{ Gender } \\
\hline Female & 51 & 46.4 \\
\hline Male & 59 & 53.6 \\
\hline \multicolumn{3}{|l|}{ Travelled out of the country } \\
\hline No & 41 & 37.3 \\
\hline Yes & 69 & 62.7 \\
\hline \multicolumn{3}{|l|}{ Purpose of travel $(n=69)$} \\
\hline Holiday & 48 & 69.6 \\
\hline Education & 8 & 11.6 \\
\hline Meeting friends or relatives & 15 & 21.7 \\
\hline Travelled with $(\mathrm{n}=69)$ & & 0.0 \\
\hline Alone & 8 & 11.6 \\
\hline Friends & 12 & 17.4 \\
\hline Family & 51 & 73.9 \\
\hline \multicolumn{3}{|l|}{ Frequency of travel in the last 5 years $(n=69)$} \\
\hline 1 & 37 & 53.6 \\
\hline 2 & 19 & 27.5 \\
\hline 3 & 6 & 8.7 \\
\hline$>3$ & 4 & 5.8 \\
\hline \multicolumn{3}{|l|}{ Visited doctor for travel health advice prior to the trip $(n=69)$} \\
\hline Yes & 47 & 68.1 \\
\hline No & 22 & 31.9 \\
\hline $\begin{array}{l}\text { Had you received travel vaccine before your last trip } \\
(n=29)\end{array}$ & 29 & 42.0 \\
\hline Hepatitis B & 22 & 75.8 \\
\hline Hepatitis A & 10 & 34.5 \\
\hline Influenza & 4 & 13.8 \\
\hline Typhoid & 2 & 6.9 \\
\hline
\end{tabular}

is a focus on infectious diseases in travel medicine. This may seem logical, as travel medicine has generally focused on pretravel vaccination and disease prophylaxis, and the continuous upgrading of knowledge that travellers receive..$^{23,24}$

In the present study, $70 \%$ of intern doctors had heard about travel vaccine and chemoprophylaxis for international travels but they were not much aware of vaccine requirement, schedule, and its importance. One-third of them had mentioned hepatitis $\mathrm{A} \& \mathrm{~B}$, JE and rabies as international travel vaccine which are commonly given in immunisation schedule of India, as well. Very few (11.8\%) were aware of the importance of yellow fever vaccination in relation to international travel (Table 2). In a study by Hassan et $\mathrm{al}^{15} \mathrm{a}$ majority of the physicians were aware of the travel vaccine and provided advice on to their client. However, in a study performed in Qatar only

$44.7 \%$ of the physicians provided pretravel medical advice to their clients, including travel vaccination. ${ }^{25}$ These findings from different studies highlight the need to sensitize physicians and health care professionals to travel medicine. Variation in study findings may be due to differences in the study population and geographical area but by emerging and re-emerging infectious disease trends all over the world, there is a need to focus on travel medicine by policy makers which helps to improve disease burden.

All individual planning should seek advice on the potential hazards in their chosen destinations and understand how best to protect their health and minimize the risk of acquiring the disease. Forward planning, appropriate preventive measures, and careful precautions can protect their health and minimize the risks of accidents and acquiring the disease. Although the medical profession and the travel industry can provide extensive help and sound advice, it remains the traveller's responsibility to seek information to understand the risks

Table 2. Knowledge About Travel Health

\begin{tabular}{lll}
\hline & No. & $\%$ \\
\hline Heard about international travel vaccination and chemoprophlaxis & 77 & 70 \\
Yes & 33 & 30 \\
No & & \\
Knowledge about vaccines & 35 & 31.8 \\
Hepatitis B & 33 & 30 \\
Hepatitis A & 33 & 30 \\
Yellow fever & 13 & 11.8 \\
Japanese encephalitis & 12 & 10.9 \\
Typhoid & 10 & 9.1 \\
Rabies & 4 & 3.6 \\
Cholera & & \\
\hline Importance of pre-travel health advice & 85 & 77.3 \\
Avoid health problem & 30 & 27.3 \\
Take vaccine & 6 & 5.5 \\
Take anti-malarial medicines & 3 & 2.7 \\
Take first aid & 3.7 \\
Don't know & & \\
\hline
\end{tabular}


involved, and to take the necessary precautions to protect their health while travelling. ${ }^{23}$ In the present study out of 69 respondents travelled internationally, 47 (68.1\%) had visited a doctor for travel health advice prior to their trip. Among the study participants who travelled internationally the reasons stated for not visiting a doctor were that they were either unaware of the importance of the matter $(47.8 \%)$ or had consulted with a family doctor (31.9\%) on phone. Reasons stated in others' studies included distressing protocols and requirement for the vaccination, cost of vaccination as well as a poor monitoring system for ensuring travel vaccination at the entry and exit points of the countries, perception of not being at risk, lack of awareness of travel diseases, lack of consideration of vaccination as an essential matter for travelling, cost of the vaccination, and side effect. ${ }^{15,26,27}$ Variation in findings compared to other studies indicate that there are poor monitoring and adherence to travel guidelines in the study area.

Today's medical intern doctors are future healthcare professionals and important members of society to combat health problems. Additionally, they are an important source of information to the general public to provide counselling, education, and prevention measures for disease when they want to travel internationally, thus the knowledge and understanding of travel medicine among them needs to be standardized. On analysing awareness and practice of the travel medicine in various aspects such as necessity, vaccine need, and time to visit physician, etc, it was found that $96.4 \%$ of the interns said that pre-travel health advice is necessary, the most common reason for pretravel advice was to avoid health problem (77.3\%) followed by vaccination (27.3\%). Out of 69 travellers, $34.5 \%$ said that a traveller should visit traveller's clinic four to five weeks before travelling; $87.3 \%$ said pretravel vaccination is necessary and $91.8 \%$ said that anti-malarial medicines are necessary (Table 3 ). The present

Table 3. Understanding Pre-travel Health

\begin{tabular}{llc}
\hline & No. & $\%$ \\
\hline Best time to visit traveller's clinic before travel (wk) & & \\
\hline $1-2$ & 18 & 16.4 \\
$2-3$ & 30 & 27.3 \\
$3-4$ & 19 & 17.3 \\
$4-5$ & 38 & 34.5 \\
Don't know & 5 & 4.5 \\
\hline Pre-travel health advice is necessary & 106 & 96.4 \\
Don't know & 4 & 3.6 \\
Yes & & \\
\hline Pre-travel vaccination is necessary & 96 & 87.3 \\
Yes & 14 & 12.7 \\
Don't know & & 80 \\
\hline Pre-travel anti-malarial treatment is necessary & 101 & 91.8 \\
\hline Yes & 9 & 8.2 \\
Don't know & 60.9 \\
\hline
\end{tabular}

\section{Resarch Highlights}

\section{What Is Already Known?}

In India, there is a poor performance of travel health counseling among travelers as well as medical professionals, and this should be important for both groups.

\section{What This Study Adds?}

The findings from the study will help to improve pretravelhealth importance among medical professionals and also will draw the attention of policy makers regarding strict monitoring and adherence to international travel guidelines among Indians to reduce travel-related diseases.

study reflects serious shortcomings with regard to awareness of vaccines and chemo-prophylaxis for international travel.

\section{Limitations}

This study could not ascertain the actual uptake of travel vaccine among the respondents as well as the full compliance with travel vaccination requirements of the various destination countries.

\section{Conclusion}

Study findings revealed unsatisfactory awareness and practice of travel medicine among medical intern doctors. Findings of the study also revealed there is need to focus on immediate attention by policy makers for strict monitoring and adherence to international travel guidelines to reduce the travel-related disease. More studies need to be conducted to ascertain the actual awareness and practices in different parts of India to generalise study findings.

\section{Authors' Contributions}

Study conception and design: JAL; Acquisition of data: KS and SG; Analysis and interpretation of data: SG and KS; Drafting of manuscript: JAL; Critical revision: KS and SG.

\section{Conflict of Interest Disclosures}

The authors declare no conflict of interest in their research.

\section{Ethical Approval}

Institutional ethical committee approval (DYPM/ CSC/15/2018, May 7, 2018) and informed consent from study participants were obtained for the study.

\section{Funding/Support \\ None.}

\section{References}

1. World Tourism Organization (UNWTO). UNWTO Tourism Highlights. UNWTO; 2011. http://mkt.unwto.org/sites/all/files/ docpdf/unwtohighlights11enhr_1.pdf.

2. Heywood AE, Watkins RE, lamsirithaworn S, Nilvarangkul K, Maclntyre CR. A cross-sectional study of pre-travel health-seeking practices among travelers departing Sydney and Bangkok airports. BMC Public Health. 2012;12:321. doi:10.1186/1471-2458-12321.

3. Lopez-Velez R, Bayas JM. Spanish travelers to high-risk areas in 
the tropics: airport survey of travel health knowledge, attitudes, and practices in vaccination and malaria prevention. J Travel Med. 2007;14(5):297-305. doi:10.1111/j.1708-8305.2007.00142.x.

4. Piyaphanee $\mathrm{W}$, Wattanagoon $\mathrm{Y}$, Silachamroon $\mathrm{U}$, Mansanguan $\mathrm{C}$, Wichianprasat $\mathrm{P}$, Walker E. Knowledge, attitudes, and practices among foreign backpackers toward malaria risk in southeast Asia. J Travel Med. 2009;16(2):101-106. doi:10.1111/j.17088305.2008.00282.x.

5. Provost S, Soto JC. Perception and knowledge about some infectious diseases among travelers from Québec, Canada. J Travel Med. 2002;9(4):184-189. doi:10.2310/7060.2002.24550.

6. Ropers G, Du Ry van Beest Holle M, Wichmann O, et al. Determinants of malaria prophylaxis among German travelers to Kenya, Senegal, and Thailand. J Travel Med. 2008;15(3):162-171. doi:10.1111/j.1708-8305.2008.00188.x.

7. Hamer DH, Connor BA. Travel health knowledge, attitudes and practices among United States travelers. J Travel Med. 2004; 11(1):23-26. doi:10.2310/7060.2004.13577.

8. Toovey S, Jamieson A, Holloway M. Travelers' knowledge, attitudes and practices on the prevention of infectious diseases: results from a study at Johannesburg International Airport. J Travel Med. 2004;11(1):16-22. doi:10.2310/7060.2004.13587.

9. Van Herck K, Van Damme P, Castelli F, et al. Knowledge, attitudes and practices in travel-related infectious diseases: the European airport survey. J Travel Med. 2004;11(1):3-8. doi:10.2310/7060.2004.13609.

10. Van Herck K, Zuckerman J, Castelli F, Van Damme P, Walker E, Steffen R. Travelers' knowledge, attitudes, and practices on prevention of infectious diseases: results from a pilot study. J Travel Med. 2003;10(2):75-78. doi:10.2310/7060.2003.31638.

11. Wilder-Smith A, Khairullah NS, Song JH, Chen CY, Torresi J. Travel health knowledge, attitudes and practices among Australasian travelers. J Travel Med. 2004;11(1):9-15. doi:10.2310/7060.2004.13600.

12. Hatz CFR, Chen LH. Pre-travel consultation. In: Keystone JS, Freedman DO, Kozarsky PE, Connor BA, Nothdurft HD, eds. Travel Medicine. 3rd ed. Philadelphia, PA: Saunders/Elsevier; 2013. p. 31-36.

13. Freedman DO, Weld LH, Kozarsky PE, et al. Spectrum of disease and relation to place of exposure among ill returned travelers. $\mathrm{N}$ Engl J Med. 2006;354(2):119-130. doi:10.1056/NEJMoa051331.

14. Chen LH, Hill DR. PIER Module: Travel Immunizations. Philadelphia, PA: American College of Physicians; 2012.

15. Hassan ZI, Afolaranmi TO. The knowledge and uptake of travel vaccine among medical doctors in a tertiary health institution in Plateau State, North Central Nigeria. Indian J Community Med. 2015;40(3):177-181. doi:10.4103/0970-0218.158861.

16. Omar F, Hassan N, Hussain H, Mana S, Awad O. Travel health, gaps in knowledge, attitudes, and practices among Dubai travellers, Dubai UAE. Int J Prev Med Res. 2015;1(3):126-131.

17. Al-Abri SS, Abdel-Hady DM, Al-Abaidani IS. Knowledge, attitudes, and practices regarding travel health among Muscat International Airport travelers in Oman: identifying the gaps and addressing the challenges. J Epidemiol Glob Health. 2016;6(2):6775. doi:10.1016/j.jegh.2016.02.003.

18. Steffen R, Rickenbach $M$, Wilhelm U, Helminger A, Schär M. Health problems after travel to developing countries. J Infect Dis. 1987;156(1):84-91. doi:10.1093/infdis/156.1.84.

19. Leggat PA. Sources of health advice given to travelers. J Travel Med. 2000;7(2):85-88. doi:10.2310/7060.2000.00027.

20. Centers for Disease Control and Prevention (CDC). CDC Health Information for International Travel 2010. Atlanta, GA: U.S. Department of Health and Human Services, Public Health Service; 2009. p. 1-4.

21. Alghamdi AH, Ibrahim AM, Al-Ghamdi MS, Ryan ET, Al-Raddadi R. Travel health in the Kingdom of Saudi Arabia: perception and practice of Saudi travelers. Int J Health Res Innov. 2014;2:25-39.

22. Steffen R, deBernardis C, Baños A. Travel epidemiology--a global perspective. Int J Antimicrob Agents. 2003;21(2):89-95. doi:10.1016/s0924-8579(02)00293-5.

23. World Health Organization (WHO). International Travel and Health. Geneva: WHO; 2012.

24. International Society of Travel Medicine. The Body of Knowledge for the Practice of Travel Medicine. Atlanta: International Society of Travel Medicine; 2006. https://www.istm.org/WebForms/ Members/MemberResources/Cert_Travhlth/Body.aspx.

25. Al-Hajri M, Bener A, Balbaid O, Eljack E. Knowledge and practice of travel medicine among primary health care physicians in Qatar. Southeast Asian J Trop Med Public Health. 2011;42(6):1546-1552.

26. Pavli A, Spilioti A, Smeti P, Patrinos S, Maltezou HC. Vaccination and malaria prevention among international travelers departing from Athens International Airport to African destinations. J Trop Med. 2014;2014:563030. doi:10.1155/2014/563030.

27. Lopez-Velez R, Bayas JM. Spanish travelers to high-risk areas in the tropics: airport survey of travel health knowledge, attitudes, and practices in vaccination and malaria prevention. J Travel Med. 2007;14(5):297-305. doi:10.1111/j.1708-8305.2007.00142.x 